\title{
Como estudantes do ensino médio acham que falam? Crenças sobre a palatalização de oclusivas e expressão da $1^{\text {a }}$ pessoa do plural
}

\author{
How do students high school think they speak? Beliefs about the palatalization of \\ alveolar stops and expression of the first person plural
}

Bruno Felipe Marques Pinheiro*

Universidade Federal de Sergipe

São Cristóvão, Sergipe, Brasil

Lucas Santos Silva**

Universidade Federal de Sergipe

São Cristóvão, Sergipe, Brasil

Paloma Batista Cardoso***

Universidade Federal de Sergipe

111

São Cristóvão, Sergipe, Brasil

\begin{abstract}
Resumo: Todo processo de variação linguística sofre influência de fatores linguísticos e extralinguísticos. Além das atitudes e julgamentos sociais, atuam as crenças linguísticas. Controlando as variantes africadas /t $\int / \mathrm{e} / \mathrm{d} 3 /$ das oclusivas dentais /t/ e /d/ antecedidas pela vogal anterior alta [i], bem como a variação no uso de nós e $a$ gente na função de sujeito da primeira pessoa do plural, este trabalho analisa as crenças que os estudantes da educação básica quanto a esses fenômenos. À luz da Sociolinguística Variacionista, na perspectiva da percepção e dos estudos sobre crenças linguísticas, constituímos um corpus com 18 entrevistas sociolinguísticas em duas escolas da rede pública de Aracaju/SE. Os resultados sugerem uma correlação entre uso, crença e julgamento das variáveis em questão, bem como a saliência na estrutura linguística e a consciência.
\end{abstract}

Palavras-chave: Crenças; Julgamento; Palatalização; Primeira pessoa do plural; Educação básica.

Abstract: The process of linguistic variation is influenced by linguistic and extralinguistic factors. Over there of attitudes and social judgement, act linguistics beliefs. Underscoring the uses of the affricated variants $/ \mathrm{t} \int / \mathrm{e}$ /dz/ of alveolar stops / t / e /d preceded by the previous high vowel [i], as well as the variation in the use of nós e a gente in the first person plural, this work carry an analysis of the beliefs that students of basic education about these phenomena. How will students evaluate the variable palatalization and first person plural, from their manifestations, whether verbal or not, in front of affective reactions? Supported by sociolinguistic variation, of in studies on language beliefs, we constitute a corpus with 18 interviews in two public school from Aracaju/SE. The results suggest a correlation between use, belief and judgment of the variables in question, as well as the salience in the linguistic structure and the phonological awareness are factors that interfere in the beliefs acquired by the speakers throughout their school process.

Keywords: Beliefs; Judgement; Palatalization; First person plural; Basic education.

* Estudante da Universidade Federal de Sergipe. E-mail: bpinnheiro@hotmail.com ** Estudante da Universidade Federal de Sergipe, bolsista CNPq. E-mail: lucas riachao@hotmail.com

*** Estudante da Universidade Federal de Sergipe, bolsista CNPq. E-mail: palomabatistacardoso@hotmail.com 


\section{INTRODUÇÃO}

Estudos sociolinguísticos de produção têm apontado que o nível de escolaridade para alguns fenômenos linguísticos é uma variável social relevante para uma mudança linguística no que tange às formas, uma vez que, no português brasileiro, "o prestígio ou estigma de um traço linguístico depende da maior ou menor consciência do falante sobre a avaliação social da regra, o que reflete nos resultados relativos à variável sociodemográfica escolarização" (FREITAG, 2016, p. 890).

Essa percepção, por sua vez, ao adentrar no ambiente escolar, interfere nos estudantes, à medida que a variação se faz presente dentro da sala de aula e o comportamento linguístico utilizado pelos falantes implica em seus usos e crenças. Partindo de uma relação entre gramática e mudança linguística, "no Brasil, a escolarização é tomada como variável genérica, controlada com a premissa de que a exposição à cultura letrada e o papel normativo da escola". (FREITAG, 2017, p. 67)

Essa consideração acarreta uma discussão: se, por um lado, no ambiente escolar, as variantes que os alunos utilizam se entram em contato, por outro lado, há a imposição de que a escola tenta ensinar para uma variante normativa, canônica. Diante desse cenário, é necessário lembrar que os Parâmetros Curriculares Nacionais de Língua Portuguesa (PCN), Plano Nacional do Livro Didático (PNLD) e Base Nacional Comum Curricular (BNCC) sinalizam para um rompimento do padrão linguístico normativo e canônico como absoluto na sala de aula. Esses documentos visam, também, instar ao professor e ao aluno reflexões sobre o funcionamento da língua sob as diferentes esferas de circulação, além de combater o preconceito linguístico presentes na sociedade que, às vezes, dá-se quando a escola usa o discurso do certo x errado. Sobre isso, Bagno (2003), afirma que:

[...] a escola tenta impor sua norma linguística como se ela fosse, de fato, a língua comum a todos os 160 milhões de brasileiros, independentemente de sua idade, de sua origem geográfica, de sua situação socioeconômica, de seu grau de escolarização. (BAGNO, 2003, p. 15).

Ainda no mesmo sentido, o Guia de Livros Didáticos do PNLD do Ensino Fundamental preconiza que o ensino de língua portuguesa deve se organizar para, dentre outros fatores, garantir ao aluno

o desenvolvimento de atitudes, competências e habilidades envolvidas na compreensão da variação linguística e no convívio democrático com a diversidade dialetal, de modo que seja evitado o preconceito e sejam valorizadas as diferentes possibilidades de expressão linguística (BRASIL, 2013, p. 16)

Essas discussões acerca do ensino de língua em sala de aula nos ajudam a refletir como essas concepções acarretam a construção de crenças por parte dos alunos na escola em relação aos fenômenos linguísticos. Além do mais, é de suma importância compreender qual é a correlação entre uso efetivamente que os alunos fazem de sua variedade linguística em relação às crenças construídas ao longo de suas vidas escolares, 
para constatar, assim, quais são as avaliações que os estudantes fazem de sua própria fala. Os estudos da sociolinguística de base variacionista já descrevem essas relações com a variável escolarização:

III

os estudos sociolinguísticos têm presumido o efeito da escola a partir do resultado da distribuição das variantes em função do nível de escolarização dos falantes estratificados em uma amostra. No entanto, a perspectiva da produção é, muitas vezes, diferente da perspectiva da percepção (FREITAG, 2017, p. 71)

No entanto, não basta somente investigar a perspectiva da produção, a Sociolinguística Variacionista já tem discutido em relação às crenças e atitudes no ambiente escolar. Os estudos de Cyranka (2007) nos ajudam a entender um pouco melhor:

Já na perspectiva dos estudos sociolinguísticos, há que se ressaltar que, dentre os problemas de base tratados pela Sociolinguística está o da relação entre crença e atitude. Dittmar (1976, p. 181) observa que a mensuração das atitudes linguísticas baseia-se em dois quadros teóricos diferentes: os mentalistas e os behavioristas. Enquanto os primeiros propõem que as atitudes sejam analisadas a partir de três componentes (afetivo, cognitivo e conativo), os behavioristas preferem considerá-las a partir apenas da dimensão afetiva (avaliativa). (CYRANKA, 2007, p. 23)

Ainda há poucos trabalhos que investigam a relação entre usos e crenças dos estudantes no processo de escolarização: o que eles efetivamente utilizam na fala e o que acham que falam. Estudos sobre crenças e atitudes, como afirma Freitag (2017, p. 75),

têm ganhado fôlego no Português Brasileiro nos últimos tempos, e podem atender às demandas de ensino de língua materna: não basta apenas ter os parâmetros de frequência de recorrência de uma dada variante, é preciso saber o valor social desta variante, em cada comunidade.

A fim de contribuir para o desvelamento do valor social de fenômenos variáveis no espaço escolar, destacamos no presente artigo a escolha de dois fenômenos: palatalização das oclusivas alveolares e variação de primeira pessoa do plural. $\mathrm{O}$ intuito é analisar as variantes africadas $/ \mathrm{t} \int / \mathrm{e} / \mathrm{d} 3 /$ das oclusivas dentais / $/ \mathrm{e} / \mathrm{d} /$ antecedidas pela vogal anterior alta [i] e as variantes "nós" e "a gente" na expressão do sujeito da primeira pessoa do plural, em entrevistas sociolinguísticas, a partir do conceito de crenças, no escopo da cognição, fruto de uma interação social e sendo moldados por processos culturais (CYRANKA, 2007). Será que os estudantes têm consciência do processo fonológico e morfossintático próprios da fala?

\section{OS FENÔMENOS VARIÁVEIS}

A seguir, apresentamos uma sumarização do que vem sendo feito em Sergipe sobre estudos dos fenômenos destacados, a realização africada de oclusivas alveolares e a expressão da primeira pessoa do plural. 


\subsection{REALIZAÇÃO AFRICADA DE OCLUSIVAS ALVEOLARES}

Do ponto de vista fisiológico, o processo de palatalização consiste no levantamento da língua para parte posterior do palato duro (CRISTÓFARO-SILVA, 2015). Esse processo ocorre quando um segmento consonantal é articulado e a língua se direciona mais para frente da cavidade bucal. No português, o processo ocorre quando as oclusivas alveolares [t] e [d] manifestam-se como africadas alveopalatais [t $\left.\int\right]$ e [dz], em contextos acompanhados de vogal alta anterior [i].

Em Sergipe, há tanto processos de palatalização progressiva - quando um ditongo decrescente antecede ao fenômeno e ocorre uma assimilação da vogal anterior alta [i], a exemplo de muito ['mü.tfu] e leitores [le.tfu.ra], socialmente estigmatizadas -, como de palatalização regressiva - variante de prestígio, quando a vogal anterior alta [i] procede ao fenômeno, como em partia [pah.'tfi.] e tarde ['tah.dfi]. Ao analisar a fala de Aracaju, SouzaNeto (2007) observou a realização de oclusivas alveolares /d/ e /t/ e constatou que há variação, embora não tenha distinguido o ambiente, se de palatalização progressiva ou regressiva.

Souza (2016) ampliou o escopo do estudo sobre a palatalização regressiva, abarcando outros municípios além de Aracaju (Lagarto e Itabaiana), com base em entrevistas sociolinguísticas. O resultado aponta para o avanço da mudança, na direção da capital ao interior. Já a palatalização progressiva é mais recorrente fora da capital, como mostram os estudos de Evangelista, Santana e Andrade (2016), em São Cristóvão, e Freitag (2015), em Lagarto, e, no espaço escolar, apresenta comportamento estigmatizado (FREITAG et alii, 2016). Pinheiro e Silva (2016) observaram que, na situação de leitura, a palatalização regressiva passa para a leitura, o que evidencia o seu valor de prestígio na comunidade.

Estes estudos permitem instanciar o valor social atribuído a cada uma das variantes da palatalização, e que podemos relacionar ao nível de saliência da variável no espaço escolar.

\subsection{VARIAÇÃO DA PRIMEIRA PESSOA DO PLURAL}

A primeira pessoa do plural tem como expressões variáveis as formas nós e a gente. A primeira, em virtude de um paradigma pronominal, que não leva em consideração a ocorrência das formas amplamente utilizadas pelos falantes. Enquanto a segunda, está associada a situações mais formais.

Lopes (1998), afirma, que a gente é a forma preferida entre falantes do português brasileiro para indicar a primeira pessoa do plural. Todavia, apesar do espaço conquistado pela variante inovadora em contextos formais e informais; orais e escritos (cf. BRUSTOLIN, 2009) nós, por ser reconhecida pelos manuais normativos da língua, desfruta de maior prestígio social. Por isso, os falantes, principalmente os estudantes em nível da educação básica, acreditam ser ela a forma ideal, correta (cf. GAMEIRO, 2009) e, consequentemente, creem em uma frequência de uso maior que a de fato. 
No Brasil, os estudos de variação linguística, apontam para uma regularização da forma a gente e uma mudança no percurso sugerindo que tal forma não é estigmatizada. Em consonância a isso, como afirma Freitag (2016, p.891),

Em Sergipe, os resultados não foram diferentes. Os resultados de investigação do paradigma da primeira pessoa do plural na posição de sujeito em quatro amostras do banco de dados Falares Sergipanos, constituídas por diferentes metodologias de coleta, visando o controle de gradientes de (in)formalidade, apontam para o predomínio da forma a gente.

Freitag; Santana e Andrade (2014) analisaram uma amostra de interação de três reuniões de um grupo religioso em um povoado de Lagarto, e perceberam uma assimetria para as duas formas nós e a gente, em contraponto com duas variáveis sociais: faixa etária e escolarização. Freitag et alii (2016) descreveram a variação da primeira pessoa do plural, em dados coletados no Colégio Estadual Atheneu Sergipense, para identificar grupos e suas interações no que tange à marcadores, estereótipos e indicadores em um ambiente escolar, apontando a preferência do uso da forma a gente em relação à nós. E, Freitag, Cardoso e Góis (2017), analisando 183 instrumentos de avaliação subjetiva em relação ao uso da $1^{a}$ pessoa do plural, evidenciam que, apesar da variante não-canônica ocorrer expressivamente, a ela é atribuído um julgamento social diferenciado. Isso acontece, segundo as autoras, em decorrência do reconhecimento, por parte dos manuais normativos da língua, de apenas uma forma para indicar a primeira pessoa do plural: nós.

Essas relações entre essas duas variedades podem serem atreladas pelas crenças que os falantes do português brasileiro têm em relação as variáveis de uso. E, essa crença em relação aos estudantes da educação básica, está atrelada pela forma canônica interligada ao contexto de escolarização. Isso tem interferência com o papel que a escola tem na formação do indivíduo e a legitimação que impõe para a utilização de nós em contraste à forma a gente. Freitag (2016) assevera que, do ponto de vista da avaliação social,

A análise dos julgamentos linguísticos mostra que a crença que os informantes destas comunidades têm em relação à forma pronominal a gente é a de que só pode ser usado em contextos menos formais, ou de muita intimidade, ou é força do hábito, um "vício de linguagem", uma forma "errada", "feia" ou "estranha". Tais crenças sugerem que este domínio apresenta alta saliência social, estando, de certa forma, no nível da consciência do falante. (FREITAG, 2016, p. 899)

Logo, faz-se importante o estudo das crenças por parte dos falantes para além de perceber a produção de uso por parte da variação em primeira pessoa, entender os fatores contextuais que está por detrás das crenças e admitir a importância do estudo da variação linguística na educação básica, para assim tentar desmistificar as crenças implantadas em relação as formas linguísticas. 


\section{A CONCEPÇÃO DE CRENÇAS NO PROCESSO DE VARIAÇÃO LINGUÍSTICA}

O estudo de fenômenos linguísticos tem se mostrado um profícuo objeto de estudo sob os vieses de diferentes disciplinas, como a Sociolinguística Variacionista, Pragmática e a Psicologia Social. Dessas, provém a perspectiva de análise baseada nas atitudes e crenças linguísticas, que levam em consideração o julgamento social que o falante faz de determinado fenômeno linguístico.

Todo processo de variação sofre influência de fatores internos e externos. Quanto a esses, a valoração social está relacionada ao modo - positivo ou negativo - como o falante percebe determinado traço e/ou variante linguística. Dessa forma, a percepção de um fenômeno linguístico "depende do julgamento do ouvinte, que correlaciona fatores sociais a traços sociolinguísticos, constituindo um padrão de consciência social na comunidade" (FREITAG, SEVERO, ROST-SNICHELOTTO, TAVARES, 2016, p. 65). À essa consciência, estão associadas as atitudes e crenças linguísticas.

As crenças de um determinado indivíduo estão ligadas a um processo cognitivo a partir de uma interação social que esse tem em convívio dentro de uma determinada comunidade com todos os seus processos culturais e sociopolíticos (CYRANKA, 2007).

As crenças são difíceis de serem alteradas, justamente pelos fatores sociais, culturais e políticos estarem já intrínsecos aos sujeitos, pois se formam desde muito cedo no indivíduo e partem de um processo cultural envoltos dentro de uma sociedade, essa, por sua vez, envolvendo também o ambiente escolar, uma vez que esse se insere na comunidade.

Delimitando essa seção para a percepção das crenças no ambiente escolar, em seu trabalho sobre atitudes e crenças no ambiente escolar, Santos (1996, p. 08) afirmava que a "crença seria uma convicção íntima, uma opinião que se adota com fé e certeza". Logo, "a crença pressupõe uma manifestação verbalizada sem reações afetivas, enquanto as atitudes podem ser manifestar de modo não verbalizável, mas permeadas por reações afetivas em relação ao objeto em questão" (FREITAG, 2016, p. 901).

No que tange ao ambiente escolar, uma vez que é o corpus deste artigo, as crenças também estão inseridas no processo educacional, bem como os processos de variação próprios da língua. Abaixo, apresentamos excertos no que se refere aos processos de palatalização, (1) a (3), e variação na expressão de primeira pessoa do plural (4) a (6), referentes à amostra para percebemos a relação com as crenças utilizadas pelos entrevistados:

(1) D1: você fala mais tia dia ou tfi dzia?

S1: dia dia

D1: você acha que tenha uma forma mais uma forma melhor do que a outra?

S1: não acho que não as duas são as mesmas coisas têm o mesmo significado (ali_joã_29_09_2016)

(2) D1: você costuma falar mais o ti dzi? OU eh no caso tia dia? ou tfi dzia?

S1: tia en falo tia

D1: tia? 


\section{S1: ih (and_joã_29_09_2016)}

(3) D1 durante o seu dia a dia você fala mais tia dia ou tfia d3ia?

S1 dia a dia?

D1 você acha que tem al/ assim alguma forma mais especial... melhor do que a outra?

S1 dia a dia é melhor (ang_joã_06_10_2016)

(4) D1: ah quando você está conversando você fala mais o nós o pronome nós ou a forma a gente?

S1: a gente

D1: você acha que tem uma dessas formas é melhor do que a outra?

S1: não... não porque vai tá se referindo às mesmas pessoas só vai só que.. um vai tá no pronome outro diferente sujeito (ali_joã_29_09_2016)

(5) D1: ah você costuma falar mais nós ou fala mais a gente?

S1: nós vai tá certo? no/ os dois eu uso os dois

D1: cê usa os dois? mas qual ... qual desses dois você acha melhor de se comunicar?

S1: nós

D1: nós?

S1: mas depende né? da situação... da situação do... do qual a pessoa vai se referir

(and_joã_29_09_2016)

(6) D1 ah quando você está conversando... você fala mais o pronome NÓS ou o a gente?

S1 a gente

D1 qual dessas formas você acha melhor?

S1 eh... eu às vezes erro um pouco nessa questão de concordância

S1 que eu não gosto muito de português

S1 (risos) (ang_joã_06_10_2016)

Percebemos, nesses excertos, que as crenças acabam se tornando posições as quais os indivíduos, neste caso, os alunos, tem em relação aos fenômenos. E, aqui, vale salientar que a escola tem um papel normatizador na construção das crenças em relação aos assuntos como gramática, língua e variação linguística (FREITAG, 2017).

Observamos, nos excertos, que a maioria dos estudantes responde as perguntas em relação às crenças com outras perguntas geralmente de cunho indagativo. A crença na eleição de determinadas variedades ditas canônicas como a forma nós e os segmentos consonantais alveolares gera-se dúvidas por parte dos alunos, uma vez que a crença se torna um constructo social e uma convicção íntima, e uma vez que desestabiliza a crença, surgem-se as dúvidas.

As crenças e atitudes são elementos constitutivos da identidade linguística dos falantes, diferenciando regiões dialetais, modeladas pelas instituições sociais. Sendo a escola um espaço em que se constroem crenças e se moldam atitudes, consideramos pertinente verificar como os formadores da consciência linguística e disseminadores dos discursos sobre a língua (FREITAG, SEVERO, ROST-SNICHELOTTTO, 2016, p. 67) 
Sendo assim, é necessário se levantar o conjunto de crenças que permeiam os estudantes, estabelecendo uma tensão entre a estrutura linguística e a social desses sujeitos, para a partir do processo de constituição da identidade, seja pela língua, ou pelo discurso, ou pelas crenças, para perceber e analisar como os fenômenos variáveis são afetados, nesse caso, o da palatalização e a primeira pessoa do plural. (cf. FREITAG; SEVERO; ROST-SNICHELOTTO; TAVARES, 2015).

\section{METODOLOGIA}

A metodologia utilizada para esta pesquisa seguiu os moldes Labovianos, a partir de entrevistas sociolinguísticas, com média de 50 a 60 min cada. Todo o corpus em análise compõe o banco de dados Falares Sergipanos (FREITAG, 2013b) e as entrevistas foram feitas com alunos do ensino médio do Colégio Estadual Ministro Petrônio Portela e do Colégio Estadual Professor João Costa, ambos localizados em Aracaju/SE.

No roteiro de entrevista, há várias perguntas referentes as diversas sequências discursivas, dentre elas: moradia, sociais e globais, fator social, lazer, educação, esporte, cultura. E, ao final da entrevista, o documentador faz perguntas sobre alguns fenômenos linguísticos que são prestigiados ou estigmatizados. Para esta pesquisa, foram utilizadas essas perguntas na análise para averiguar às crenças e julgamentos que os alunos fazem sobre o próprio uso da língua. Dentre elas, estão:

- Você acha que fala mais tia, dia? Ou tfi, dzia?

- Você acha que um é melhor do que o outro para falar?

- Você acha que fala mais oito, doido? Ou otfo, do dzo?

- Você acha que um é melhor do que o outro para falar?

- Quando você está conversando, você fala mais o "nós" ou fala mais o "a gente"?

- Qual dessas formas você acha melhor?

Depois de constituídas as amostras, as entrevistas realizadas foram transcritas no programa computacional Elan (SLOETJES; WITTENBURG, 2008). Após as transcrições das documentações orais, começamos as análises. Para o fenômeno da palatalização, foram analisados os primeiros 10 contextos da variação fonológica de cada entrevista, constituindo 799 ocorrências. Identificamo-las e estabelecemos as seguintes variáveis, apresentadas individualmente e cruzadas: uso, julgamento, crença e sexo/gênero.

Em relação à variação da primeira pessoa, coletamos 252 ocorrências de nós e a gente. Localizamo-las, nas duas formas em função de sujeito e estabelecemos as seguintes variáveis: uso, julgamento, crença e sexo.

Após esse processo, todas as ocorrências dos fenômenos foram decodificadas mediante às variáveis linguísticas, sociais e de percepção (crenças) e submetemos os dados para análise estatística descritiva, com realização de teste qui-quadrado, para observar a aleatoriedade da distribuição das respostas, com o pacote R (R CORE TEAM, 2017). 


\section{RESULTADOS E DISCUSSÃO}

\subsection{PALATALIZAÇÃO DAS OCLUSIVAS ALVEOLARES}

Quanto ao processo de palatalização, percebemos os dados relativos ao uso, à crença e ao julgamento que os estudantes do ensino médio fazem da variável fonológica da palatalização. Como apresentado no gráfico 1 da figura 1, a quantidade de falantes que utilizam a forma africada (106) ainda é mínima. Por sua vez, nos resultados sobre crenças, gráfico 2 da figura 1, houve uma correspondência para o uso, uma vez que (549) disseram que não palatalizavam.

Uso (1)

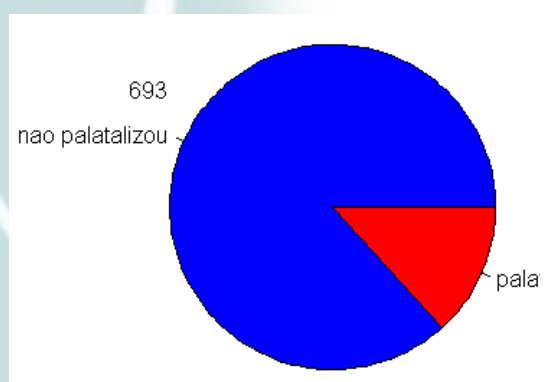

Crença (2)

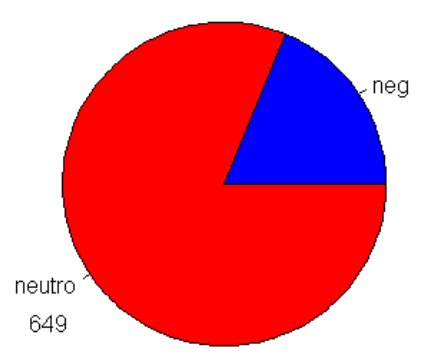

Julgamento (3)

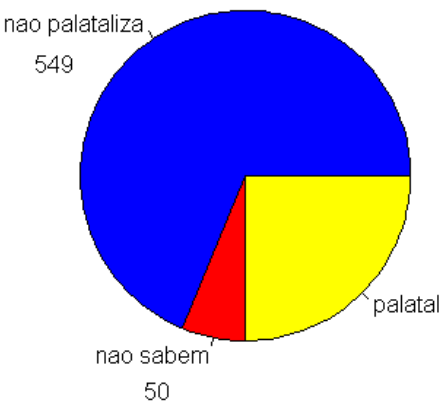

Figura 1: Distribuição das ocorrências de palatalização.

Esses resultados convergem e corroboram com o que Richardson (1996) apresenta sobre a relação de crenças e atitudes, ele apresenta três formas: i) relação de causa-efeito; ii) relação interativa; iii) relação hermenêutica.

Nesses resultados, percebe-se uma relação de causa e efeito, que conforme Cyranka (2007, p. 22), "embora não se trate de uma relação simples, ela existe, de fato, visto que há uma relação recíproca de influência de crenças e ações". Há uma influência em relação ao uso que os alunos utilizam com as crenças adquiridas por eles.

Essa influência pode se dar por fatores contextuais dentro do ambiente escolar, ao passo que, em Sergipe, a forma privilegiada é das oclusivas alveolares, o constructo de crenças adquiridas ao longo de sua estada na escola por parte dos alunos, também corresponderá para a crença da não palatalização.

Aqui, observa-se o papel normativo da escola por uma variedade normativa das oclusivas, no caso de Sergipe, e o reforço para a crença de uma não realização africada. Todavia, é necessário lembrar de que, conforme os estudos sobre o fenômeno em Sergipe, está ocorrendo um processo de mudança para a variável africada das oclusivas. 
Já em relação ao julgamento, o gráfico 3 da figura 1 aponta que os informantes se mantiveram neutros em sua maioria (649), ou seja, aqui, notamos que o contexto fonológico não foi tão sensível para o nível de consciência dos falantes. Isso se dá pelo grau de saliência, tanto linguístico como social da palatalização, esse não é tão sensível para se ter uma explanação externa e interna da língua em relação às crenças, isso devido ao contexto fonológico - lugar e ponto de articulação - que ocorre o processo de palatalização.

Percebemos, dessa forma, a relação de saliência com a consciência do falante, como afirma Freitag (2016, p. 901):

a saliência pode ser resultado da distribuição da variável (Yaeger-Dror 1993) e processos de acomodação conscientes ocorrem, com traços cognitivos mais salientes enquanto processos de acomodação inconsciente ocorrem com traços cognitivos menos salientes.

Por fim, chama-nos atenção o resultado do julgamento da palatalização, pois nenhum participante valorou o fenômeno como positivo. Isso nos leva a crer, que correlacionando o fator de saliência com o processo de acomodação dos estudantes, no que diz respeito ao julgamento, é muito mais inconsciente do que consciente para a valoração do fenômeno.

Ao relacionar uso, crença e julgamento, notamos que o nível de consciência social é um aspecto relevante, pois se os nossos resultados apontam para uma conservação maior de uso e crenças para a forma das oclusivas, sugerimos que os sujeitos da pesquisa demonstraram uma barreira para as formas de uso africadas.

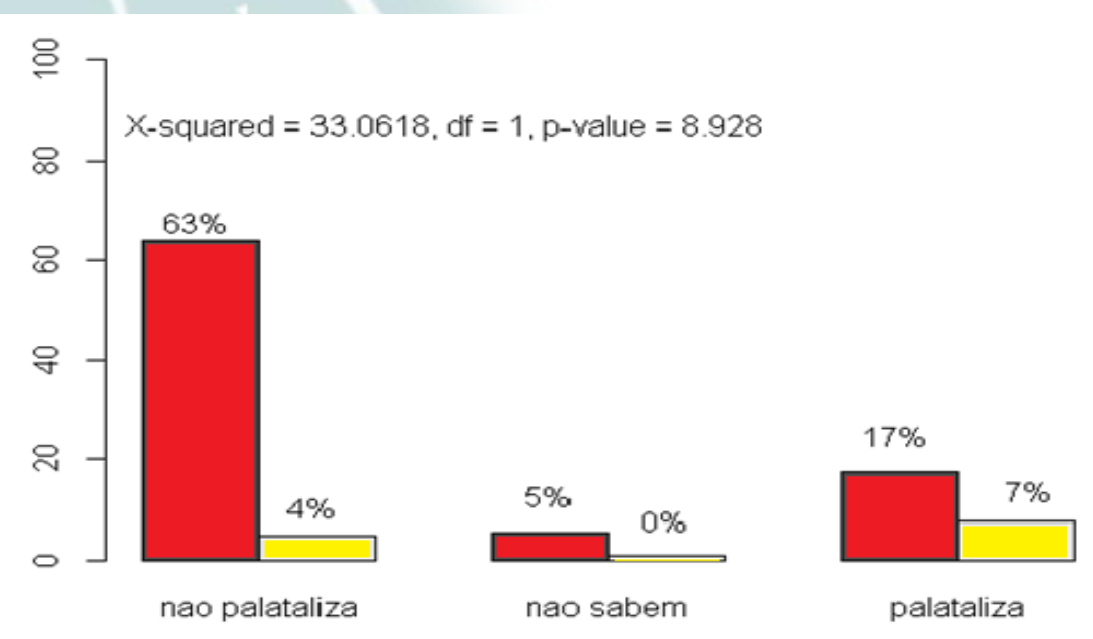

Figura 2: Distribuição do uso da palatalização quanto à crença.

Para as crenças, é de se notar o maior resultado para a não palatalização (63\%), conforme o gráfico da figura 2. Já o julgamento, o maior resultado é neutro para o fenômeno fonológico $(69,2 \%)$, conforme o gráfico da figura 3. Ao passo que no tange ao sexo, no gráfico da figura 4 , há uma semelhança entre meninos e meninas para a não 
palatalização do fenômeno, apesar das meninas palatalizarem mais que os meninos, corroborando com os resultados de estudos anteriores sobre o fenômeno em análise (SOUZA-NETO, 2014; SOUZA, 2016, PINHEIRO; SILVA, 2016).

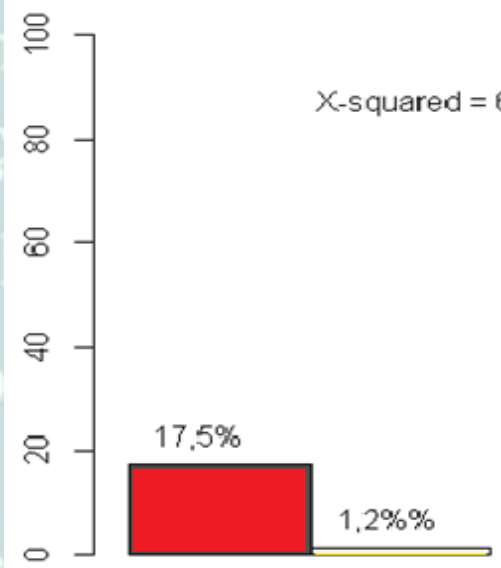

negativo

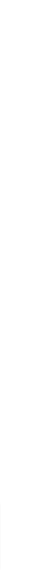

neutro

Figura 3: Distribuição do uso da palatalização quanto ao julgamento.

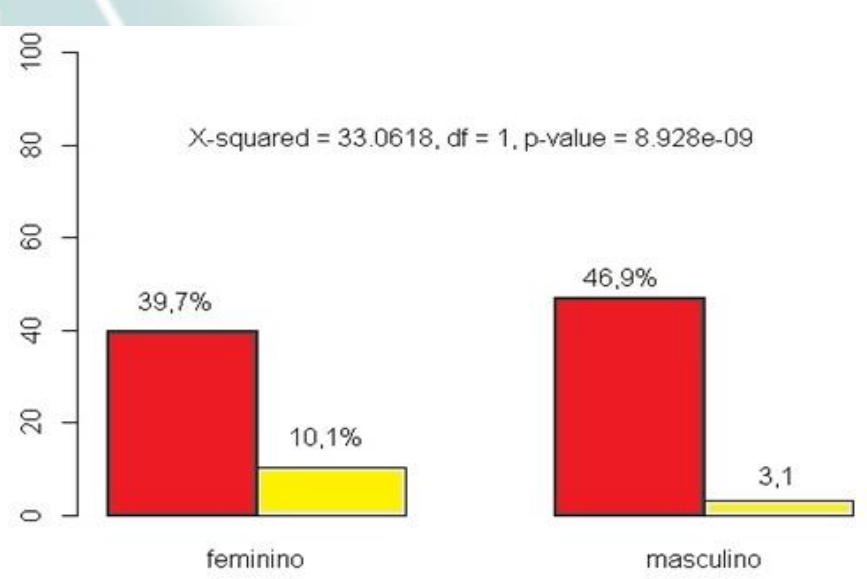

Figura 4: Distribuição do uso da palatalização quanto ao sexo/gênero.

Logo, o comportamento linguístico da produção utilizado pelos estudantes corresponde às crenças desses informantes, sugerindo, assim, que do ponto de vista do julgamento social a palatalização é um fenômeno do tipo marcador e, também, torna-se um estereótipo, considerando que a forma africada é uma barreira linguística para os estudantes.

Com isso, podemos perceber a relação das crenças com o uso que os falantes fazem das variáveis. Além disso, percebe-se a necessidade de no ambiente escolar haver uma reflexão no que concerne à variação linguística e às variedades existentes na língua para ajudar no processo de ensino-aprendizagem dos alunos. (RICHARDSON, 1996) 
O julgamento dado pelos falantes pode estar relacionado com a manifestação de polidez que os estudantes têm em sala de aula, uma vez que as formas linguísticas padrões ainda são as oclusivas alveolares. Dessa forma, os falantes podem estar implicados para um nível de monitoramento maior e, assim, não utilizam as formas africadas, até mesmo por considerarem uma variante estereotipada. Para o tratamento de crenças, no que se refere ao fenômeno da palatalização essas apresentam também um caráter avaliativo, e, por consequência, interfere na maneira que os alunos se referem à variação linguística (CYRANKA, 2007).

\subsection{VARIAÇÃO DA PRIMEIRA PESSOA DO PLURAL}

Como vimos, em Sergipe, replicando o que acontece no Brasil, conforme Lopes (1998), a variante a gente é a preferida entre os falantes para indicar a primeira pessoa do plural. Tal assertiva também é confirmada nos resultados obtidos no presente trabalho, uma vez que das (252) ocorrências da primeira pessoa do plural, (223) são da forma a gente, conforme vemos no gráfico 1 da figura 5 . A variante canônica apresenta um resultado bastante menor em relação à não-canônica, com apenas (29) ocorrências, conforme gráfico 2 da figura 5 .
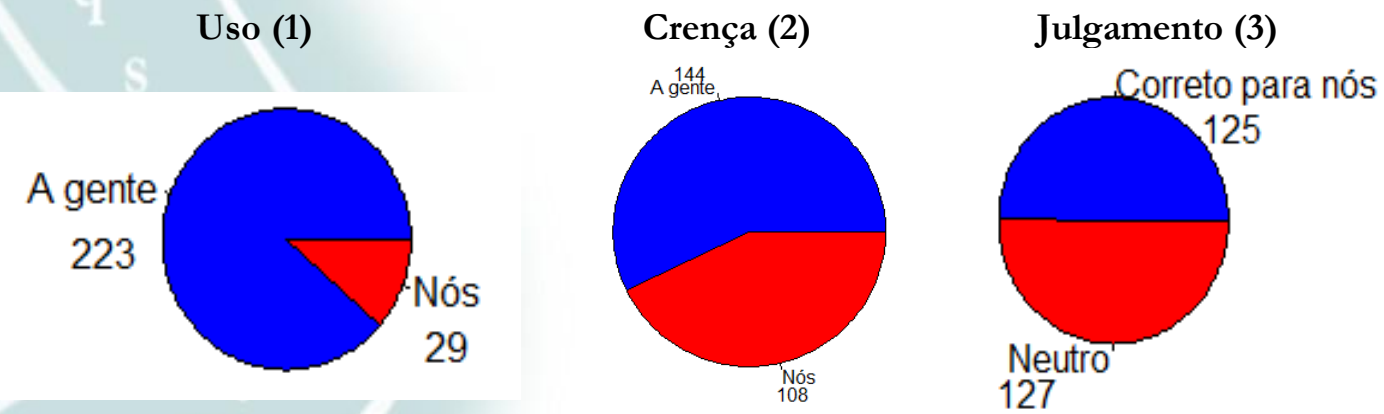

Figura 5: Distribuição das ocorrências da primeira pessoa do plural.

O julgamento de um fenômeno de variação depende da percepção dos falantes de determinada comunidade de fala. Entre os alunos dos colégios Ministro Petrônio Portela e João Costa, nota-se que a diferença entre correto para nós e neutro é bastante pequena (125) e (127), respectivamente, conforme gráfico 3 da figura 5.

A partir dos resultados obtidos para a variável julgamento, podemos dizer que, apesar dos falantes, majoritariamente, julgarem que o uso de uma ou outra variável é indiferente, o julgamento positivo para o uso de nós é maior que seu uso efetivo, o que aponta para um comportamento diferenciado para as duas formas.

Quanto à crença no uso da primeira pessoa do plural, figura 6, observamos tendência para a variante não-canônica, o que reforça as evidências apontadas para a não estigmatização da forma a gente. Todavia, cabe ressaltarmos que a crença dos estudantes quanto ao uso da variante canônica é maior que seu uso efetivo. 


\section{Revista

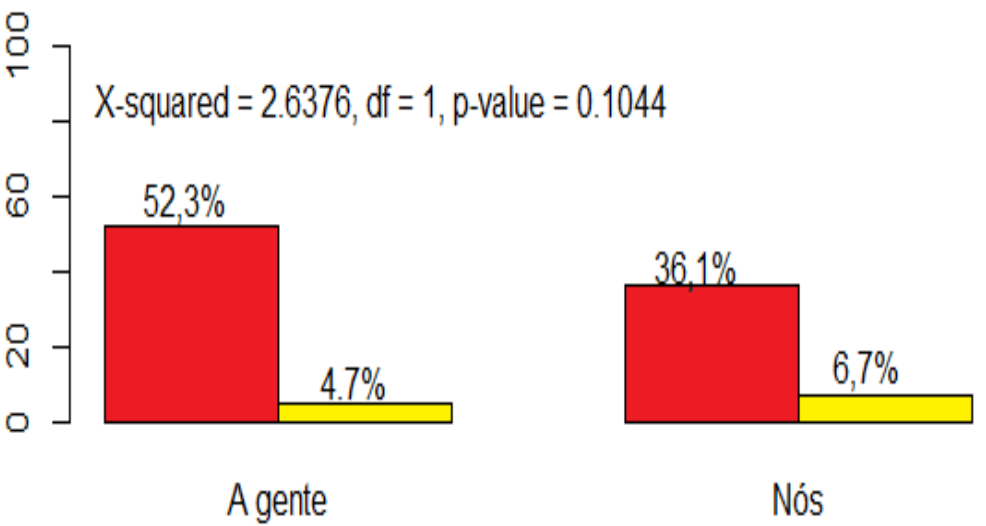

Figura 6: Distribuição do uso quanto à crença na primeira pessoa do plural.

Ao compararmos uso e julgamento, figura 7 , observamos que apontam que a variante inovadora não é percebida negativamente. Apesar de 45,2\% dos informantes julgarem o uso de nós correto, $43,2 \%$ julgam que o uso de uma ou outra forma é indiferente.

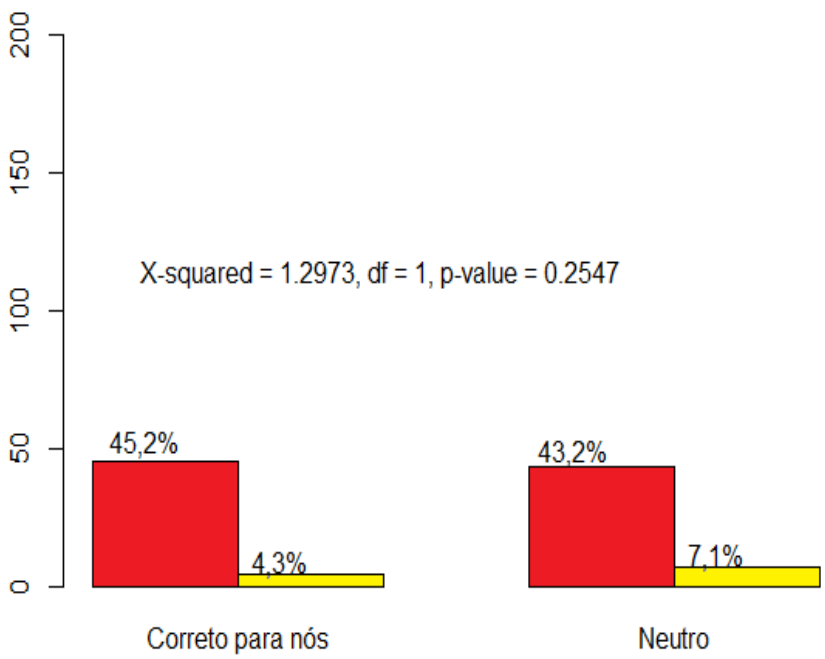

Figura 7: Distribuição do uso quanto ao julgamento da primeira pessoa do plural. 

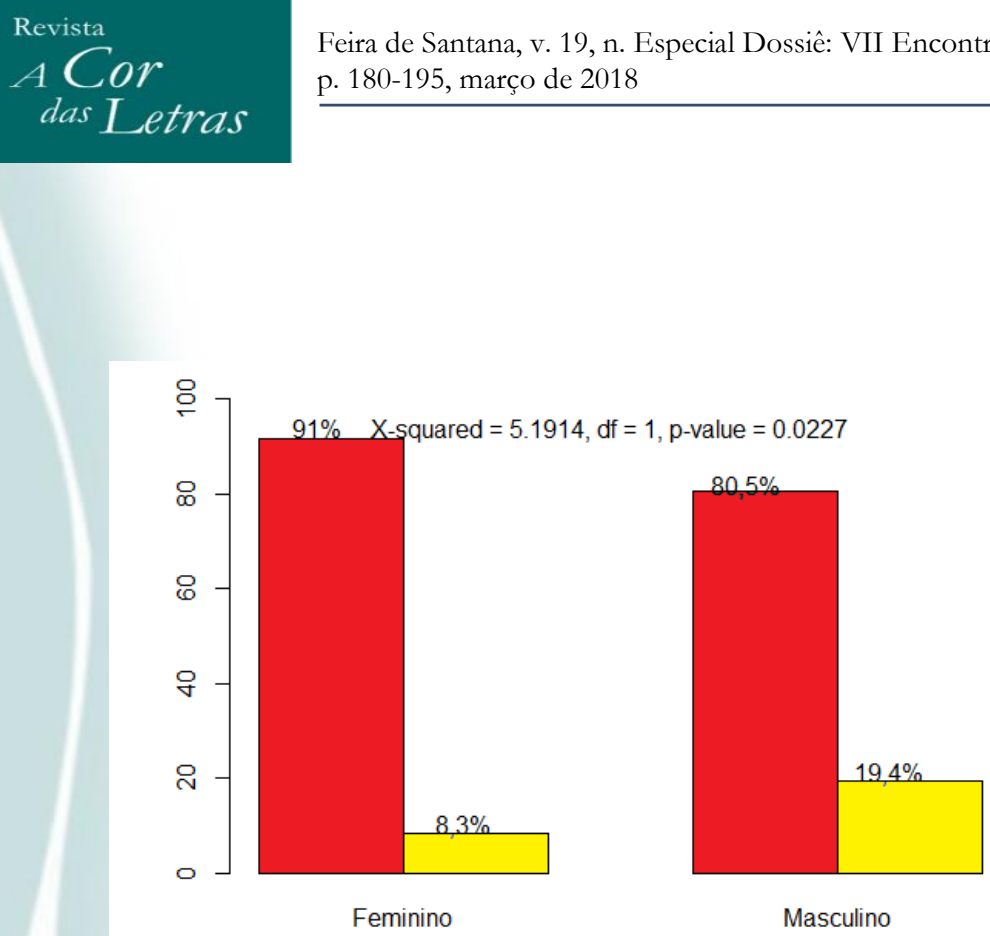

Figura 8: Distribuição do uso da primeira pessoa do plural quanto ao sexo

O sexo/gênero do informante se mostra significativo no condicionamento das crenças e usos, figura 8. Estudantes do sexo feminino tendem ao uso da variante inovadora: a gente apresenta $91 \%$ de uso. Para nós, o resultado é menor: 8,3\%. Já estudantes do sexo masculino apresentam $80,5 \%$ para o uso de a gente e $19,4 \%$ para uso da variante canônica, evidenciando o caráter conservador desse sexo quanto à variação da primeira pessoa do plural.

\section{CONSIDERAÇÕES FINAIS}

Os resultados obtidos neste trabalho apontam a preferência de a gente para indicar a primeira pessoa do plural. Os falantes creem que o uso da forma inovadora é predominante, o que de fato acontece. Todavia, cabe ressaltarmos que a crença no uso da variante canônica é privilegiada, portanto, é maior que seu uso efetivo, o que evidencia a diferença no julgamento social associado a nós e a gente.

Percebemos, também, que, se por um lado, os estudos sobre palatalização encaminham para uma mudança de oclusivas para africadas, com a implementação das formas $/ \mathrm{t} \int / \mathrm{e} / \mathrm{d} 3 /$, mesmo de forma ainda lenta, por outro lado, a avaliação social se encaminha para uma direção contrária, isto é, o comportamento linguístico das variantes corresponde às crenças e o julgamento que os falantes fazem. Logo, os dois fenômenos estudados são do tipo marcadores.

Os resultados sugerem que, no que tange à variação linguística, as formas eleitas refletem papel que a escola tem de normatizar falares dito "cultos" (FREITAG, 2017). Isso só nos leva a crer o quão ainda se faz necessário, no ambiente escolar, promover discussões acerca de variação linguística e retirar estereótipos e formas eleitas de falares "corretos". 


\section{REFERÊNCIAS}

CYRANKA, Lucia Furtado de Mendonça. Atitudes lingüisticas de alunos de escolas públicas de Juiz de Fora - MG. 2007. 174 f. Tese (Doutorado em Estudos Linguísticos) Instituto de Letras, Universidade Federal Fluminense, Niterói, 2007.

FREITAG, Raquel Meister Ko. A mudança linguística, a gramática e a escola. Revista PerCursos, v. 18, n.37, p. 63 - 91, 2017.

FREITAG, Raquel Meister Ko. Banco de dados falares sergipanos. Working Papers em Lingüística 14.2: 156-164, 2013.

FREITAG, Raquel Meister Ko. Socio-stylistic aspects of linguistic variation: schooling and monitoring effects. Acta Scientiarum. Language and Culture, v. 37, n. 2, p. 127-136, 2015.

FREITAG, Raquel Meister Ko. Uso, crença e atitudes na variação na primeira pessoa do plural no português brasileiro. D.E.L.T.A., n. 32, v. 4, p. 889-917, 2016.

FREITAG, Raquel Meister Ko.; CARDOSO, Paloma Batista; GOIS, Paula Yasmin; A percepção da variação na primeira pessoa do plural: efeitos do monitoramento estilístico e urbanização. In: LOPES, N. da Silva; CARVALHO, C. dos Santos; SOUZA, C. M. Borges de. (orgs.) Fala e contexto no português brasileiro: estudos sobre variação e mudança linguisticas. Salvador: EDUNEB, a sair.

FREITAG, Raquel Meister Ko.; SANTANA, Cristiane Conceição; ANDRADE, Thais Regina Conceição; SOUSA, Valéria Santos. Avaliação e variação linguística: estereótipos, marcadores e indicadores em uma comunidade escolar. In: FREITAG, Raquel Meister Ko, SEVERO, Cristine Gorski, GORSKI, Edair Maria. Sociolinguística e política linguística: olhares contemporâneos. São Paulo: Blücher, 2016, p. 139-160.

FREITAG, Raquel Meister Ko.; SANTANA, Cristiane Conceição; ANDRADE, Thaís Regina Conceição. 2014. Práticas constitutivas do povoado Açų̧inho. Ambivalências, 2.3, p. 194-217, 2015.

FREITAG, Raquel Meister Ko.; SEVERO, Cristine Gorski; ROST-SNICHELOTTO, Claudia Andrea; TAVARES, Maria Alice. Como o brasileiro acha que fala? Desafios e propostas para a caracterização do "português brasileiro". Signo y Seña-Revista del Instituto de Lingüística 28: 65-87.

FREITAG, Raquel Meister Ko.; SEVERO, Cristine Gösrki, ROST-SNICHELOTTO, Cláudia Andrea, TAVARES, Maria Alice. Como os brasileiros acham que falam? Percepções sociolinguísticas de universitários do Sul e do Nordeste. Todas as letras, São Paulo, v. 18, n. 2, p. 64-84, maio/ago. 2016.

GAMEIRO, Maria Beatriz. A variação da concordância verbal na terceira pessoa do plural em redações escolares do ensino fundamental e médio: uma avaliação de fatores linguísticos e sociais. Tese (doutorado). Universidade Estadual Paulista, Araraquara, 2009.

LABOV, William. Padrões sociolinguísticos. São Paulo: Parábola, 2008. 
LOPES, Célia Regina dos Santos. Nós e a gente no português falado culto do Brasil. DELTA, v. 14, n. 2, p. 405-422, 1998.

PINHEIRO, Bruno Felipe Marques. SILVA, Lucas Silva. Processos fonológicos que passam da fala para a leitura: palatalização das oclusivas alveolares na leitura oral dos alunos do Colégio Estadual Ministro Petrônio Portela - Aracaju/SE. Anais Eletrônicos da XXVI Jornada do Grupo de Estudos Linguísticos do Nordeste. Recife: Editora Pipa, 2016, p. 313-325.

R CORE TEAM (2017). R: A language and environment for statistical computing. R Foundation for Statistical Computing. Vienna, Austria. URL:< https://www.R-project.org/.>

RICHARDSON, Virginia. The role of attitudes and beliefs in learning to teach. In: SIKULA, J. (Org.). Handbook of research on teacher education. 2. ed. New York: Macmillan, 1996. p. 102-119.

SANTANA, Flávia Regina de; et. alii. Palatalização das oclusivas dentais /t/ e /d/ antecedidas por glide em São Cristóvão/SE. Revista Sociodioleto, v. 6, nº 18, mai. 2016. (p. 622-637).

SANTOS, Emmanoel. Certo ou errado?: atitudes e crenças no ensino da língua portuguesa. Rio de Janeiro: Graphia, 1996.

SOUZA NETO, Antônio Félix. Realizações dos fonemas /t/ e /d/ em Aracaju-Sergipe. São III Cristóvão: Editora da Universidade Federal de Sergipe, 2014.

SOUZA, Gládisson Garcia Aragão. Palatização de oclusivas alveolares em Sergipe. Dissertação (Mestrado em Letras) - Universidade Federal de Sergipe. São Cristóvão, 2016, 71 f. : il.

Recebido em: 15/12/2017

Aprovado em: 26/01/2018

Publicado em: 01/03/2018 